\title{
The Effect of e-Book on Students' Learning Styles A Study in Terengganu, Malaysia
}

\author{
W. Roslina, S. Fahmy, Z. Fariha, N. Haslinda, A. Yacob, N. Sukinah, N. Suhana \\ Faculty of Computer, Media and Technology \\ TATI University College, Terengganu, Malaysia \\ \{lina, fahmy, ziti, haslinda, azliza, sukinah, suhana\}@tatiuc.edu.my
}

\begin{abstract}
Electronic Book or e-Book has been adopted in the education system throughout the worlddue to its positive effect to the learning environment. This paper is a part of a continuous research effort in the Malaysian e-Book project with the aim of investigating the effect of e-Book on students' learning style. A questionnaire is administered to a small sample of school children in the State of Terengganu. Results show that the IT-literacy rate among respondents is high (87\%); e-Book is mostly used in school (53\%), but not fully utilized and adopted (40\%); the main reason for using e-Book is academic related $(98.6 \%)$; and class sessions are perceived more enjoyable $(95.8 \%)$ and interesting $(90.1 \%)$. The use of e-Book has also open new communication channels between friends although traditional communication channels are still used between family members. Respondents also report that they are more willing to do homework with the aid of e-Book as opposed to the traditional paper-and-pencil method. It is hoped that this study has given new insights regarding the effect of eBook to students' learning style, thus building a solid foundation for future research in the Malaysian e-Book project.
\end{abstract}

Keywords : e-Book; Malaysia; Terengganu; Learning.

\section{INTRODUCTION}

At the turn of the century, individuals and organizations alike are turning to digital content for both academic and leisure purposes with the introduction of a new line of computer software and peripheral - the Electronic Book or e-Book. In 2011 for example, Amazon.com reported that its e-Book sales have exceeded its printed book sales and shortly after that in 2012, more e-Books hit the market including PocketBook Touch, Kbuuk (cloud-based e-Book), iBooks and Kindle Paperwhite.e-Book has paved new ways and created new market segments as users around the world turn to a more 'greener' and portable means of reading.

Recognizing its potential in academia, e-Book has been adopted in the education system in many countries [1-2].To date, more than 20 countries including Malaysia have utilized e-Book in their education system reaping positive effects from studentand teacher groups [3]. The e-Book project in Malaysia is spearheaded by the State of Terengganu with the distribution of e-Book to primary school childrenaged 10-12 years old. As of 2012, more than 92,000 students have received e-Book and benefitted from this project.

The State of Terengganu is located in the east-coast of Peninsular Malaysia covering an area of $13,035 \mathrm{~km}^{2}$. Terengganu has a population of $1,015,776$ with $51 \%$ of the population reside in urban areas. There are 346 primary schools across the state with approximately 146,000 students and 11,000 teachers (January 2011 data). Considering the vast number of schools and students involved in the e-Book project, this work also acts as a pilot study before implementation at the state level is carried out.

This work is a part of a continuous research effort in the Malaysian e-Book project. Previous works have proposed directions for research in this area [4-5] and recommend an approach for evaluating software quality in e-Book [6-7]. The aim of this paper is to investigate the effect of e-Book in students' learning style, a direction proposed by [4]. In order to achieve this aim, three objectives have been identified (1) To assess changes in learning attitude and experience; (2) To assess changes in communication channels; (3) To assess changes in social activity.

This paper is organized as follow: background of the study is presented in Section 1. Section 2 presents a brief background and related studies in e-Book around the world. Methodology is presented in Section3 while results and discussions are carried out in Section 4. Finally, conclusion and directions for future research are presented in Section 5.

\section{LITERATURE REVIEW}

The first instance of 'electronic book' in literature is found in 1985 [8-10] although some authors argues that e-Book started as early as the late 1940s with the introduction of la Enciclopedia Mecánica in 1949 - a system that allows readers 'to stop at a specific page' and 'zooming in a particular area of the text' [11]. Others say e-Book started in 1960s, triggered by the NLS[12] and FRESS projects [13-14] - systems that provide readers with extensive hyperlinking and graphical manipulation capabilities. However, many believe that Michael Hart invented the e-Book as we know it today in 1971 [1516].Hart created the first electronic document by typing the United States Declaration of Independence into a computerand Project Gutenbergwas launched afterwards to create electronic copies of texts and books[15]. 
Early implementation of e-Book includes Dynabook and Data Discman before advances in computer science saw Barnes \& Noble Nook, Amazon Kindle, Apple iPad and Google eBooks joined the market. Most e-Books today are computerized representations of physical books. The content can be as simple as scanned pages to a more 'lively' one, where animation and sounds are incorporated into the pages. Some e-Books are also integrated with assessment tools and dedicated learning environments such as the e-Book in Malaysia [4].

The Malaysian e-Book is a based on the IntelClassmate PC [17-18]. Some of the content and applications are locally developed which include digital textbooks, dictionary and academic assignment and management system, resembling a Learning Management System. The e-Book is used in traditional classroom teaching (off-line), test administration (on-line), and in smart classrooms.

There are numerous research efforts in the field of e-Book spanning across disciplines [19-22] and geographical locations such as Thailand [23], Singapore, Malaysia, Indonesia[24], Japan and China. This paper does not only report the effect of e-Book in the disciplines of pedagogy and sociology, but also the implementation of e-Book in the South-East Asian region especially Malaysia.

\section{METHODOLOGY}

Determining students' learning styles towards e-Book represents an important stage in predicting the adoption of certain behavior. After overseeing the literature review and choosing the analysis models, this research was conducted through a questionnaire developed through exploratory research.

\section{A. Participant}

The participants in this study are a group of primary school because of e-book had been provided as a trial basis for those grades only. The participants consisted of three groups from standard 4, 5 and 6 students. The number of respondent who completed the survey is 142 students involved 69 male and 73 female from Sekolah Kebangsaan Teluk Kalong, Kemaman. All participants have used e-book in/outside the school.

\section{B. Instrumentation}

This study was conducted through a questionnaire approach to study the students' behaviors towards e-Book. The questionnaire approach is choosing rather than face-to-face or telephone interview because of time constraint and it is very costly. The instrument used in this study is divided into 3 sections:

- $\quad$ Section 1: Demographic profile.

- Section 2: Assessment of e-Book usage.

- Section 3: Assessment of perceived advantage by using e-Book

\section{Procedure}

The questionnaire was administered through the class teacher to comply with the Ministry's and school's policy. Respondents were briefed on the purpose of the study where verbal and written instructions were given. The respondents were then asked to complete the questionnaire under close supervision of the class teacher.

Data was processed and analyzed using SPSS (v 12.0) where the instrument was also evaluated to test the reliability and validity of data.

\section{RESULTS AND DISCUSSION}

A total of 120 questionnaires were distributed with a return rate of $95 \%$.The set was handed to the school and collected after 2 weeks. The respondents and teachers reported several ambiguous terms in the questionnaire which were then clarified by the authors. This is expected as respondents in this study are children between the ages of 10 to 12. As such, several terms used in the questionnaire might be too technical or confusing to them.

\section{A. Demograhic Profile}

The respondents comprise of $49 \%$ male and $51 \%$ female students; where $28.9 \%$ are Year 4 students, $33.1 \%$ (Year 5) and $38 \%$ (Year 6).All respondents are of Malay ethic origin and majority of the respondents $(87 \%)$ have some experience using computer and surfing the Internet prior to the e-Book program.

The demographic profile of respondents slightly differs from the population. Based on 2011 data, the number of primary school children in Terengganu is 145,520 with $51.3 \%$ of them is male whilst $48.7 \%$ is female. Since Malay make up $94.7 \%$ of the population in Terengganu, ethnicity of the respondents can be accepted. Other ethnic groups in Terengganu include Chinese $(2.6 \%)$, Indian $(0.2 \%)$, and others $(2.4 \%)$

It is interesting to find that the IT-literacy rate of respondents is high (more than $80 \%$ ). This can be attributed to the Kampung WiFi project announced in 2010 to bridge the digital divide between rural and urban communities in Malaysia by offering free wireless access [25].

\section{B. e-Book Usage}

Results show that respondents spend most of the time using eBook at school $(53 \%)$ rather than at home $(38 \%) .31 \%$ of the respondents spend less than 1 hour using the e-Book on a daily basis, $42.3 \%$ spend between $1-4$ hours and $17.6 \%$ spend more than 4 hours(Figure 1).

Results also show that $98.6 \%$ of the respondents use eBook for academic-related activities such as homework, $87.3 \%$ surfing the Internet, $81.7 \%$ reading electronic text book, $64.8 \%$ playing games and $45.8 \%$ use e-Book for online networking activities such Facebook, Twitter and chatting (Figure 2). 


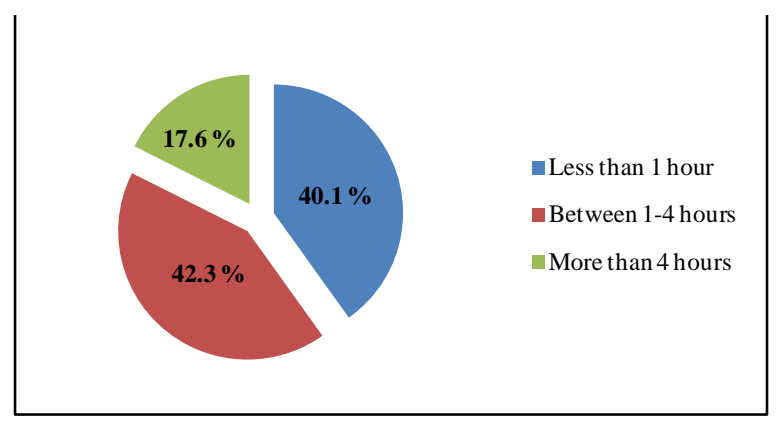

Figure 1: Daily e-Book Usage

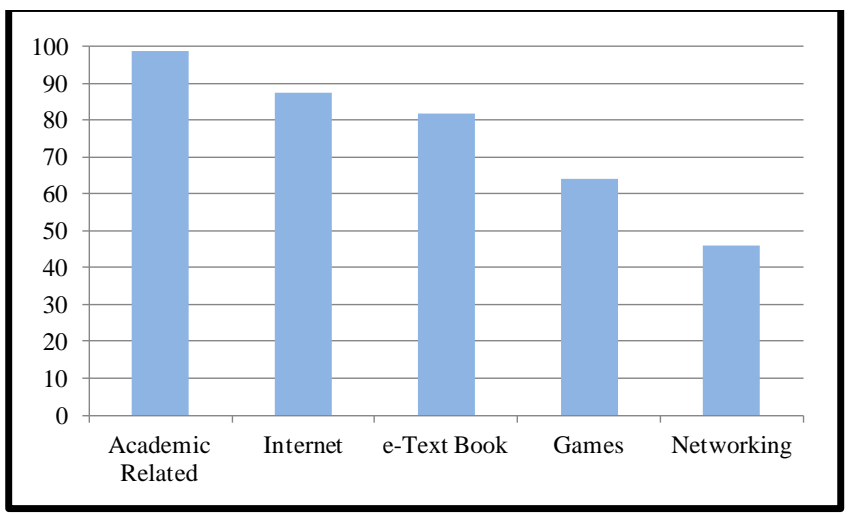

Figure 2: e-Purpose of Using e-Book

These indicate that although e-Book is mostly used in school, it is not fully utilized as almost $60 \%$ of the respondents only use it up to 4 hours on a given day. This also suggests that the use of e-Book has yet to be fully adopted in class. The use of e-Book is mainly for academic related activities and reading electronic text book. It is also noted that the use of e-Book for surfing the Internet and online networking activities are high, confirming earlier observation that most of the respondents are IT-literate.

\section{Perceived Advantage of Using e-Book}

Table 1 illustrates the perceived advantage of using e-Book where it is recorded high in P1, P3 and P6 with a percentage of $90.1 \%, 95.8 \%$ and $90.8 \%$ respectively. The respondents felt that 'learning is more interesting', 'learning is more enjoyable' and 'homework is easier' with e-Book.

These findings are expected as the e-Book is new medium for teaching and learning activities, making class sessions more enjoyable and interesting. The use of multimedia applications might also be a contributing factor in these findings.

These findings are also expected since the use of e-Book would open new communication channels (on-line) and thus, making students spend less time for outdoor activities.

In order to identify correlations between the perceived advantages, a series of statistical analysis were carried out. This is to further understand (and confirm) the effects of e-Book on learning style.
TABLE 1 PERCEIVED ADVANTAGE OF USING E-BOOK

\begin{tabular}{|c|c|c|}
\hline \multirow{2}{*}{ PERCEIVED } & \multicolumn{2}{|c|}{ PERCENTAGE ( \%) } \\
\cline { 2 - 3 } ADVANTAGE & Yes & No \\
\hline & & \\
P1 & 90.1 & 9.9 \\
P2 & 73.9 & 26.1 \\
P3 & 95.8 & 4.2 \\
P4 & 36.6 & 63.4 \\
P5 & 3.5 & 96.5 \\
P6 & 90.8 & 9.2 \\
P7 & 65.5 & 34.5 \\
P8 & 50.0 & 50.0 \\
P9 & 28.2 & 71.8 \\
P10 & 4.2 & 95.8 \\
& & \\
\hline
\end{tabular}

Table 2 displays results of the analysis where is a positive relationship between 'like to use e-Book' and 'like to do homework' is recorded with a correlation value of .161. There is also a significant relationship between 'like to use e-Book' and 'learning is more interesting' with a correlation value of .142.These prove that students are more willing to do their homework with the aid of e-Book as opposed to the traditional paper-and-pencil method. It also proves that the use of e-Book as a tool in education is supported by the respondents by making learning activities more interesting.

TABLE 2 CORRELATION OF PERCEPTIONS

\begin{tabular}{|l|c|c|}
\hline \multicolumn{1}{|c|}{ PERCEPTIONS } & $\begin{array}{c}\text { PEARSON } \\
\text { CORRELATION }\end{array}$ & $\begin{array}{c}\text { SIG. } \\
\text { (1-TAILED) }\end{array}$ \\
\hline $\begin{array}{l}\text { Like to use e-Book } \\
\text { and Like to do homework }\end{array}$ & $.161^{*}$ & .028 \\
$\begin{array}{l}\text { Spendingtime using e-Book } \\
\text { and Spending time outdoor }\end{array}$ & .051 & .274 \\
$\begin{array}{l}\text { Spending time using e-Book } \\
\text { and Communication with family } \\
\text { members }\end{array}$ & .045 & .298 \\
$\begin{array}{l}\text { Spending time outdoor } \\
\text { and Online networking }\end{array}$ & .053 & .265 \\
$\begin{array}{l}\text { Like to use e-Book and } \\
\text { Learning is more interesting }\end{array}$ & $.142 *$ & .046 \\
\hline
\end{tabular}

Results found weak correlations between 'spending time using e-Book' and 'spending time outdoor'; and 'spending time outdoor' and 'online networking' with values of .51 and 0.53 respectively. As such, it can be said that time spent using eBook does not affect time spent for outdoor activities and online networking. Nevertheless, these findings warrant further test due to the sample size in this study compared to the population.

There is also no significant correlation between 'spending time using e-Book' and 'communication with family members'. Taking into context the earlier findings in Table 1 'using $e$ Book makes me communicate more frequently with my family members'; this would suggest that students are still using traditional communication channels amongst family members. 
It is expected that the respondents would use new (on-line) communication channels with the use of e-Book. Since this is not the case, then the recorded improve in communication might suggest that respondents are sharing knowledge with family members, or perhaps, teaching them how to use e-Book. If this is the case, then we would expect to see an increase in IT-literacy and Internet users in Malaysia in the near future.

\section{CONCLUSION AND FUTURE WORK}

This paper has presented the effects of e-Book on primary school children learning style in Malaysia. A questionnaire was administered to a sample of 120 school children in the duration of 2 weeks' time. Data was analyzed using SPSS and results show that the demographic profile of respondents is slightly different from the population in terms of gender distribution. However, the IT-literacy rate of respondents is more than $80 \%$.

Results show that e-Book is mostly used in school, but it is not fully utilized. Respondents report that the main reason for using e-Book is for academic related activities and reading electronic text book. $e-B o o k$ is perceived as making class sessions more enjoyable and interesting; and also open new communication channels.

Results also indicate that students'learning style has changed where they are more willing to do their homework with the aid of e-Book; does not forsake outdoor activities with the use of e-Book; and use new communication channels between friends although traditional communication channel is still maintained amongst family members.

Direction for future research include the effect of e-Book according to gender; assessment of Internet activity of students; identification of communication channels used; and the breakdown of students activity regarding academic and social interaction. It is hoped that this study has given new insights regarding the effect of e-Book to students' learning style. Albeit the small sample size, this study has built a solid foundation for future research in the Malaysian e-Book project in order to meet its objectives.

\section{ACKNOWLEDGMENT}

The authors would like to express their sincerest gratitude to the Terengganu State Government for their input regarding the e-Book project in Malaysia.

\section{REFERENCES}

[1] E. Y. Susan, and S. Zsuzsanna (2011). "Using an E-Book to Teach Technology: Effects On Student Performance", Proceedings of the $49^{\text {th }}$ SIGMIS annual conference on Computer Personnel Research.

[2] A. A. Mutalib, A. Alwi, and S. N. A. Salam (2009). "The Acceptance Of EBook Readers Among Malaysian Children", Faculty of Information Technology Universiti Utara Malaysia, Sintok, Malaysia.

[3] S. Kachala (1998). "Report On The Effectiveness Of Technology In Schools". Software Publishers Association.

[4] W. Roslina, S. Fahmy, A. Yaacob, N. Haslinda \& Z. Fariha (2012). "Research Directions for e-Book: A Malaysian Perspective". International Journal of Information Technology \& Computer Science, Vol. $5 \mathrm{Sep} / \mathrm{Oct}$.
[5] W. Roslina, S. Fahmy, N. Haslinda, A. Yaacob, N. Aziz, N. Sulaiman \& Z. Fariha (2012). "Research Direction for ICT in Education: Case of the e-Book Program in Terengganu". TATIUC Research and Innovation Exhibition (TARIE 2012), May $18^{\text {th }}-19^{\text {th }}$, Kuala Terengganu, Malaysia.

[6] S. Fahmy, N. Haslinda, W. Roslina \& Z. Fariha (2012). "Evaluating the Quality of Software in e-Book Using the ISO 9126 Model". International Journal of Control and Automation, Vol. 5, No. 2, June.

[7] N. Haslinda, S. Fahmy, W. Roslina, A. Yaacob, N. Aziz., N.Sulaiman \& Z. Fariha (2012). "Assessing The Software Quality In e-Book Using The ISO 9126 Model'. TATIUC Research and Innovation Exhibition (TARIE 2012), May 18th-19th, Kuala Terengganu, Malaysia.

[8] Edwin D. Reilly. (2003). "Milestones in Computer Science and Information Technology", p. 85. Greenwood Publishing Group.

[9] S Hamm (1998). "Bits \& Bytes: Making E-Books Easier on the Eyes," Business

[10] N. Yankelovich, N. Meyrowitz, \& A. van Dam. "Reading and Writing the Electronic Book". IEEE Computer 18(10), October 1985.

[11] L. Moran (2012). Think the E-reader is a modern day marvel? Think again. Daily News http://www.nydailynews.com/news/world/e-readermodern-day-marvel-article-1.1250136.Last accessed March 2013.

[12] D. Englebart (1986). "The Augmented Knowledge Workshop". Proceedings of the ACM Conference on the History of Personal Workstations.

[13] S. Carmody, W. Gross, T.Nelson, D. Rice, \&A. van Dam (1969). "A Hypertext Editing System for the $1360 "$. Proceedings of the $2^{\text {nd }}$ University of Illinois Conference on Computer Graphics, pp. 291-330.

[14] A. van Dam \&D. Rice (1970). "Computers and Publishing: Writing, Editing and Printing". Advances in Computers 10, pp. 145-174.

[15] A. Flood (8 September 2011). "Michael Hart, inventor of the ebook, dies aged 64". The Guardian (London).

[16] W. Grimes (8 September 2011). "Michael Hart, a Pioneer of E-Books, Dies at 64". The New York Times.

[17] R. Wilson and M. Landoni (2003). "Evaluating The Usability Of PortableElectronic Books," Proceedings of the 2003 ACM Symposium onApplied Computing.

[18] A. Azza, and L. J. Zhongyu (2011). "Model of E-Reading Process for ESchoolBook in Libya", International Journal of Information Retrieval Research,vol. 1, no. 3.

[19] A. Dillon (1992). "Reading from the Paper versus Screens: A Critical Review of the Empirical Literature". Ergonomics, 35(10), 1297-1326.

[20] C. Van de Velde \& M. von Grünau (2003). "Tracking Eye Movements While Reading: Printing Press Versus The Cathode Ray Tube". Proceedings of the $26^{\text {th }}$ European Conference on Visual Perception, Paris, France, ECVP, 107.

[21] D. Karahoca, A. Karahoca, A. Karaoglu, B. Gulluoglu, \&E. Arifoglu (2010). "Evaluation Of Web Based Learning On Student Achievement In Primary School Computer Courses," Procedia - Social and Behavioral Sciences, vol. 2, no. 2, pp. 5813-5819, Jan. 2010.

[22] University of Liverpool eBook Study: part 2, (2010) "A Survey of eBook Usage and Perceptions at the University of Liverpool", White Paper, Springer 11/10. V7671

[23] R. Pruengkarn, P. Praneetpolgrang, and A. Srivihok(2005). "An Evaluation Model for E-Learning Websites in Thailand University," $5^{\text {th }}$ IEEE International Conference on Advanced Learning Technologies, 2005. ICALT 2005, pp. 161- 162.

[24] P. McFarlane(2006). "Developing a Culturally Specific E-Learning Website," $7^{\text {th }}$ International Conference on Information Technology Based Higher Education and Training, 2006. ITHET '06, pp.473-480.

[25] Syahrul Fahmy, Akhyari Nasir \& Nooraida Shamsuddin (2012). "Wireless Network Attack: Raising the Awareness of Kampung WiFi Residents". International Conference on Computer \& Information Science (ICCIS 2012). June 12-14, Kuala Lumpur, Malaysia. 